\title{
在 $450-550^{\circ} \mathrm{C}$ 下原位激光制备 高 $T_{\mathrm{c}}$ 超导薄膜*
}

安承武范永昌 陆冬生 李再光

(华中理工大学、激光技术国家实验室,武汉 430074)

\section{关诃诃激光应用、超导薄膜、原位生长、低温制备}

然而, 实用的制备超导薄膜的方法是被称之为低温制备法 ${ }^{[1.2)}$ 或原位低温制备法 ${ }^{[3}$. 这种 方法是指在相对低的温度下就可制取性能优良的高 $\mathrm{T}_{\mathrm{c}}$ 超导薄漠, 而且薄膜与基片间的反应 被大大减小. 所以, 只要能够制取优质的超导薄膜, 在制备过程中所需温度越低, 这种制备 技术的适用性就越大. 到目前为止, 在较低的温度下 $\left(600-780^{\circ} \mathrm{C}\right)$ 制取性能较优的高 $\mathrm{T}_{\mathrm{c}}$ 超 导薄膜已有不少报道 ${ }^{[1-7]}$. 按文献 [7]. 要使所制薄膜的零电阻温度 $T_{c o}$ 高且转变宽度 $\Delta T$ 小, 基片加热温度须达 $780^{\circ} \mathrm{C}$. 但是, 我们的研究结果表明, 基片温度可以比 $780^{\circ} \mathrm{C}$ 低得多而 制取 $\mathrm{T}_{\text {co }}$ 很高的优质超导薄膜. 这里, 我们首次报道基片加热温度仅在 $450-550^{\circ} \mathrm{C}$ 之间, 也 没有附加放电等离子体辅助, 利用单一激讯束剥离超导靶材并兼激活氧气的技术. 直接原位制 成了 $\mathrm{T}_{\text {co }}$ 高达 $91.5 \mathrm{~K}$ 的 $\mathrm{Y}-\mathrm{Ba}-\mathrm{Cu}-\mathrm{O}$ 超导薄膜.

利用激光剥离技术淀织 $\mathrm{Y}-\mathrm{Ba}-\mathrm{Cu}-\mathrm{O}$ 超导薄膜的系统已在文献 [8] 中进行了描述, 这里 仅叙述原位制取超导薄膜的条件. 在本研究中, 超导决材 $\mathrm{YBa}_{2} \mathrm{Cu}_{3} \mathrm{O}_{7-x}$ 被选作激光剥离的靶; 二氧化锆单晶作为生长薄膜的基片; 真空室中充以约 $30 \mathrm{~Pa}$ 的流动氧气; 氧气喷射方向正对基 片; 人射到靶面的激光能量密度约 $3-4 \mathrm{~J} / \mathrm{cm}^{2}$; 入射的激光束首先经过氧气喷嘴上方与喷人 的氧气流作用后再抵达靶面; 激光以每秒 5 次的重复频率工作约 $15 \mathrm{~min}$. 薄膜淀积后, 在羓 气环境下被冷却到室温。

利用上述过程和条件制取的薄嗼, 光滑且黑亮, 看上去如同镜面, 在无需退火的情况下, 就 具有很好的超导性能. 利用直流四点探测方法, 测得它们的零电阻温度一般均高于 $84 \mathrm{~K}$, 甚 至高达 $91.5 \mathrm{~K}$, 其与基片加热温度有关, 且转变宽度 $\Delta T$ 只有约 $2 \mathrm{~K}$. 典型的 $R-T$ 特性如 图 1 所示. 可以看出, 在较低的基片温度范围内, 基片加热温度越高, 薄膜的零电阻温度也越 高. 这一事实说明, 在较低的温度下,制备性能优异的超导薄膜具有较大的难度.

为了考察原位激身制备的超导薄膛的临界电流密度 $J_{c}$, 选择性能较好的薄膜, 用激光将 其烧蚀成一条大约 $100 \mu \mathrm{m}$ 宽的条带, 其厚度已由 Talysurf 5-120 型粗粘度仪测得约为 5000 $\AA$. 在 $77 \mathrm{~K}$ 时, 该条带上可通过的电流密度约为 $10^{5} \mathrm{~A} / \mathrm{cm}^{2}$ 量级。

图 2 为所制备的 $\mathrm{Y}-\mathrm{Ba}-\mathrm{Cu}-\mathrm{O}$ 超导薄膜的 $\mathrm{X}$ 射线衍射图谱. 可以看出, 此膜是择优取向 生长的, 这与文献 [9] 的结论是一致的. 为观察薄膜的显微组织, 图 3 给出了薄膜表面的扫描 显微图, 显然, 原位制备的超导薄号, 其晶粒要细微行多, 昆体取向要规则得多. 但是, 从显微 结构图可以看出, 原位制备的薄膜表面留有未结晶的颗粒, 这是激光剥离所致的结果 ${ }^{[10]}$. 所以,

- 国家数育要员会博士点基金资助项目. 


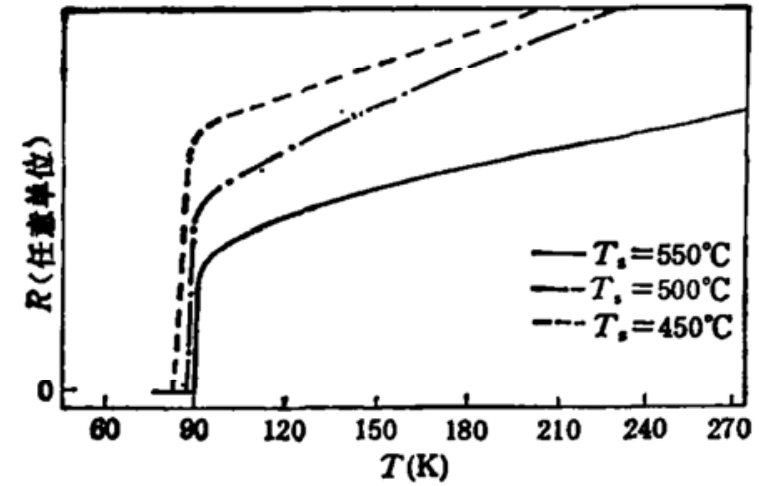

图 1 不同的基片温度下原位㥢光制备的 $\mathrm{Y}-\mathrm{Ba}-\mathrm{Cu}-\mathrm{O}$ 薄膜的 $R-T$ 特性

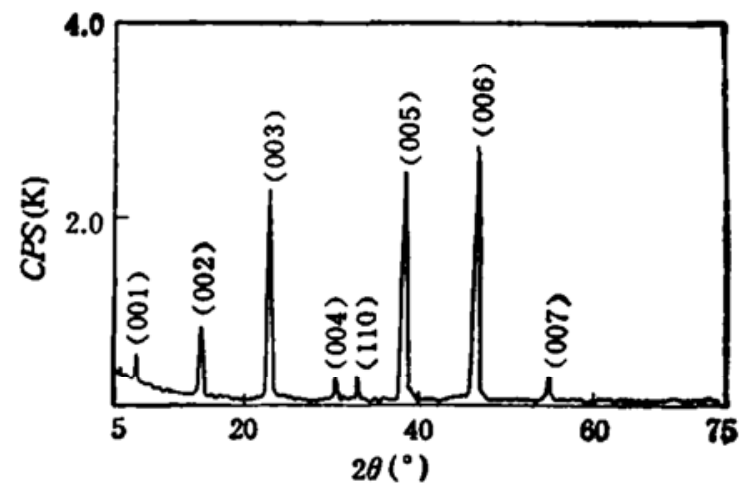

图 2 所制备的 $\mathrm{Y}-\mathrm{Ba}-\mathrm{Cu}-\mathrm{O}$ 薄膜的 X 射线 衍射谱

从这一点来看, 澈光淀积超导薄膜也存在一定的缺陷, 需作进一步的研究来对其进行改善.

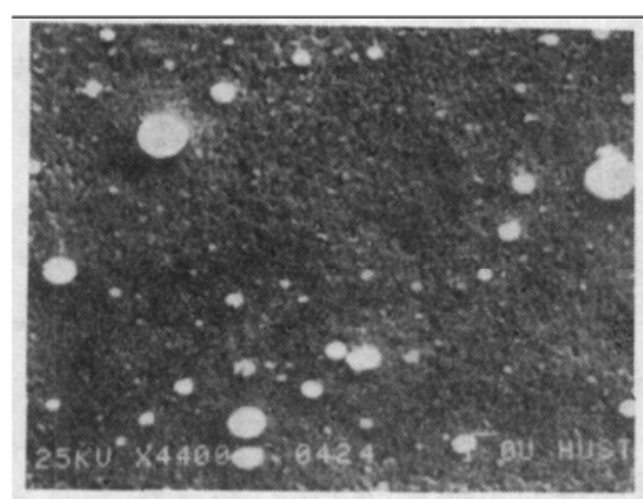

a

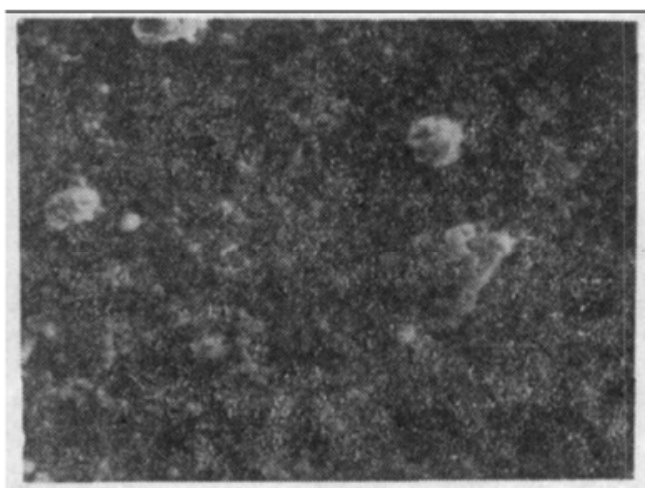

b

图 3 薄膜的显微组织

a. 原位制备的样品; b. 高温遍火制备的样品

总之, 我们利用准分子激光剥离超导乹,在基片温度仅为 $450-550^{\circ} \mathrm{C}$ 的情况下, 未附加放 电等离子体辅助, 未经后退火处竹, 直接制成了性能优异的 $\mathrm{Y}-\mathrm{Ba}-\mathrm{Cu}-\mathrm{O}$ 超导薄膜, 其 $T_{\mathrm{co}}$ 达 $91.5 \mathrm{~K}, J_{\mathrm{c}}$ 达 $10^{5} \mathrm{~A} / \mathrm{cm}^{2}$. 能够取得成功的关键: 一是喷氧流先经激光束作用而使氧气被激 活; 再是真空室中氧气分压的提高, 保证有足够氧被腚积到薄膜之中和抑制已腚积到薄膜中的 羍的外扩散.

致谢：感谢梁俊文副教授给予实验上的大力帮助，并进行了有益的讨论.

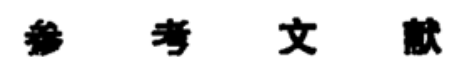

[1] Wu, X. D. et al., Appl. Phys. Lest, 52(1988), 754.

[2] Chang, C. C. et al., ibid., 53(1988), 517.

[ 3 ] Sigh, R. K. et al., ibid, 54(1989), 2271.

[4] Roes, B. et al., ibid., 53(1988), 1557.

[ 5 ] Lathrop, D. K. et al., ibid., 51(1987), 1554.

[ 6] Michikami, O. et al., Jpn. J. Appl. Phys., 26(1987), L1199.

[7] Frôhlingsdorf, J. et al., J. of Less-Common Metals, 151(1989), 407.

[8] An, C. W. et al., Chinese Science Bulletin, 35(1990), 371.

[9] Chan, S. W. et al., American Institute of Physics Conference Proceedings, 1988, 165: 88.

[10] Koren, G. et al., Appl. Phys. Letz, 55(1989), 2450. 